\title{
Vermiform Appendix Inside the Sac: Uncommon Case of Inguinal Hernia
}

\author{
Edoardo Guida $\cdot$ Federica Pederiva $\cdot$ Daniela Codrich $\cdot$ \\ Jurgen Schleef
}

Received: 12 August 2013 / Accepted: 4 November 2013 / Published online: 19 December 2013

(C) Dr. K C Chaudhuri Foundation 2013

A 2-y-old male, weighting $10 \mathrm{~kg}$, was admitted to authors institute for recurrent swelling in the right groin. No pain, redness or other symptoms were described.

Testicles were scrotal. Suspecting a right inguinal hernia, the authors decided to perform a planned inguinal herniotomy. Two months after the diagnosis, the patient was hospitalized and underwent surgical exploration through a right inguinal incision.

After opening the roof of inguinal canal, hernia sac was identified and the appendix was found inside it. The authors decided not to perform appendectomy, because the appendix was normal (Fig. 1). Therefore they only reduced the appendix into the abdomen and closed the basis of the sac though a biodegradable suture.

No antibiotic therapy was given. The patient did not require any analgesic therapy after surgery and was discharged the same evening.

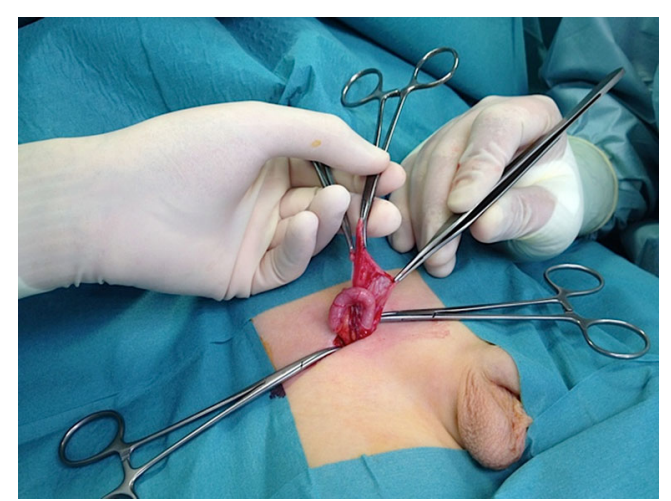

Fig. 1 Photograph of the normal vermiform appendix on opening of hernia sac

\section{E. Guida $(\bowtie) \cdot$ F. Pederiva $\cdot$ D. Codrich $\cdot$ J. Schleef}

Department of Pediatric Surgery, Institute for Maternal and Child Health-IRCCS Burlo Garofolo, Via dell'Istria, 65/1, 34137 Trieste, Italy

e-mail: edoardoguida@libero.it
On a 6-mo follow-up, no complications were seen.

Amyand's hernia is defined as an inguinal hernia containing the vermiform appendix [1-3]. Some authors suggest appendectomy in case of young patients with normal appendix within an inguinal hernia [1-3]. The authors believe that appendectomy can be avoided in young patients, in case of normal appendix, by simply reducing appendix into the abdomen. Infact, in addition to the immunological function, the possible roles of appendix have been rediscovered today. It has uses in the MACE and Mitrofanoff procedures and has been used in case of ureteral damage and for other reconstructive techniques [4-7].

\section{Contribution Jurgen Schleef will act as guarantor for this paper.}

Conflict of Interest None.

Role of Funding Source None.

\section{References}

1. Constantine S. Computed tomography appearances of Amyand hernia. J Comput Assist Tomogr. 2009;33:359-62.

2. Losanoff JE, Basson MD. Amyand hernia: What lies beneath-a proposed classification scheme to determine management. Am Surg. 2007;73:1288-90.

3. Piedade C, Reis AJ. Amyand's hernia in a 6-week-old infant: A delayed diagnosis. Case Rep Pediatr. 2013;2013:758171.

4. Levitt M, Peña A. Update on pediatric faecal incontinence. Eur J Pediatr Surg. 2009; 19:1-9.

5. Farrugia MK, Malone PS. Educational article: The Mitrofanoff procedure. J Pediatr Urol. 2010;6:330-7.

6. Shen X, Xv M, Liu G, Wu Y, Lin H, Geng H. Ureteral replacement with appendix in a pediatric group: A report of two cases and review of the literature. Eur J Pediatr Surg. 2012;22:329-31.

7. Chen SH, Yeong EK, Tang YB, Chen HC. Free and pedicled appendix transfer for various reconstructive procedures. Ann Plast Surg. 2012;69:602-6. 